\title{
Obscure gastrointestinal bleeding: An approach to management
}

\author{
JK Marshall MD MSc FRCPC, OA Lesi MD, RH Hunt MD FRCP FRCPC FACG
}

JK Marshall, OA Lesi, RH Hunt. Obscure gastrointestinal bleeding: An approach to management. Can J Gastroenterol 1999;14(2):111-118. Obscure gastrointestinal bleeding provides an uncommon but frustrating and resource-intensive challenge for clinicians. Such patients hemorrhage recurrently from sites within the gastrointestinal tract that are not detected by routine endoscopy or radiography, and require a special diagnostic approach to localize or exclude less common bleeding sources such as small bowel angioectasia or neoplasia. The differential diagnosis of obscure gastrointestinal hemorrhage is discussed, and the performance of available endoscopic, radiological and surgical diagnostic tools including enteroscopy are examined critically. A stepwise management algorithm that progresses from the history and physical examination to surgical exploration is offered to facilitate early and efficient diagnosis.

Key Words: Diagnosis; Gastrointestinal hemorrhage; Review; Therapy

\section{Saignement gastro-intestinal occulte : une approche thérapeutique}

\begin{abstract}
RÉSUMÉ : Pour le clinicien, les saignements gastro-intestinaux occultes posent un défi rare mais frustrant, et taxant sur le plan des ressources. Ces patients saignent à répétition de divers points de leur tractus digestif qui ne sont pas décelés au moyen de l'endoscopie ou de la radiographie de routine et exigent une approche diagnostique spéciale pour localiser ou exclure les sources moins fréquentes de saignement, comme l'angiectasie ou la néoplasie du grêle. Le diagnostic différentiel de l'hémorragie gastro-intestinale occulte est abordé, de même que le rendement des outils diagnostiques endoscopiques, radiologiques et chirurgicaux offerts, y compris l'entéroscopie. Un algorithme de traitement par étape, qui va de l'anamnèse à l'examen médical et à l'exploration chirurgicale, est proposé pour promouvoir un diagnostic précoce et exact.
\end{abstract}


TABLE 1

Reasons for delayed diagnosis in patients with obscure gastrointestinal hemorrhage

Inaccessibility of bleeding site to routine radiography and/or endoscopy Intermittent or slow rate of bleeding

Inconclusive evidence of bleeding from potential lesion

Subtle/atypical or rare lesion

\section{TABLE 2 \\ Diagnoses to consider in the evaluation of obscure gastrointestinal hemorrhage}

Degenerative angioectasia
Hereditary hemorrhagic telangiectasia
Watermelon stomach
Portal hypertensive gastropathy
Dieulafoy lesions
Small bowel neoplasms
Benign
$\quad$ Adenoma
$\quad$ Leiomyoma
Lipoma
Malignant
Adenocarcinoma
Lymphoma
Carcinoid
Small bowel diverticula
Meckel's
Enteric duplication cysts
Other

hemorrhage. Less commonly, the causal lesion may be subtle, rare or in an unusual location such that it is not recognized by the examining physician. These reasons for delayed diagnosis in obscure gastrointestinal bleeding are summarized in Table 1.

\section{ETIOLOGY}

In most patients who present with acute and overt gastrointestinal hemorrhage, prompt investigation by way of clinical assessment and endoscopy of the upper or lower gastrointestinal tract provides a satisfactory diagnosis. Hematemesis, melena and/or disproportionate elevation of the blood urea nitrate level suggest an upper gastrointestinal lesion. Overt upper gastrointestinal hemorrhage is most commonly attributed to peptic ulcer disease, Mallory-Weiss tears or esophageal varices. Hemorrhage distal to the ligament of Treitz more often presents with gross hematochezia and usually results from hemorrhoids, polyps, colorectal carcinoma, vascular malformations, inflammatory bowel disease or diverticulosis.
However, among patients with obscure gastrointestinal blood loss, a different differential diagnosis must be considered and in a different order of probability (Table 2).

Angioectasias: In most series, mucosal vascular abnormalities are the most common source of hemorrhage in patients who present with recurrent but obscure gastrointestinal bleeding (2). Various terms including 'angiodysplasia', 'vascular ectasia', 'telangiectasia' and 'hemangioma' have been used synonymously to describe these lesions, leading to some confusion in the literature. It has been suggested that the hereditary lesions of the Osler-Weber-Rendu and 'blue rubber bleb nevus' syndromes should be distinguished from the presumably degenerative lesions of advancing age and those associated with chronic renal insufficiency, aortic stenosis and local irradiation (3). Camilleri et al (4) proposed a classification scheme based on the size and type of vessel affected, and the presence or absence of concomitant somatic and dermatological features, but this classification scheme claimed an unproven distinction in morphology among ' $\mathrm{a}$ ngiodysplasia', 'telangiectasia' and 'hemangiomata', and has not been widely adopted. As a general descriptor, the term 'angioectasia' has been promoted recently by an international working group in endoscopic terminology (5).

Congenital or hereditary angioectasias typically are found in patients under 50 years of age $(2,6)$. While these lesions can occur anywhere in the gastrointestinal tract, those that present with obscure hemorrhage are usually found in the jejunum and proximal ileum. Patients with hereditary hemorrhagic telangiectasia (HHT), or Osler-Weber-Rendu syndrome, may suffer from frequent epistaxis and may be aware of a family history of similar bleeding episodes. HHT also may occur in association with von Willebrand's disease (7). In female patients with HHT, the rate of bleeding may be altered by the menstrual cycle, pregnancy, menopause or hormone supplementation $(4,8,9)$. Further clues to the diagnosis of HHT can be found by close inspection of the skin and oropharynx for additional vascular lesions.

Degenerative angioectasias are commonly referred to as angiodysplasia and are a significant source of hemorrhage in patients over 60 years of age. While they are localized most frequently to the cecum and ascending colon, the lesions can also occur throughout the gastrointestinal tract (10). Boley et al (11) suggested that degenerative angioectasias result from partial obstruction of submucosal veins where they traverse the longitudinal and circular layers of the muscularis propria. The resulting pressure gradient may lead to incompetence of the precapillary sphincter and development of direct arteriovenous communication.

An unusual form of angioectasia, occurring in the upper gastrointestinal tract, is the gastric antral vascular ectasia (GAVE), or watermelon stomach. Although this lesion has characteristic endoscopic and histological features, its appearance can be easily confused with gastritis by an inexperienced endoscopist (12). In some patients, GAVE may be indistinguishable from portal hypertensive gastropathy, both endoscopically and histologically, particularly in the absence of associated features of portal hypertension. However, 
portal hypertensive gastropathy, unlike GAVE, does not respond to endoscopic thermal or laser ablation (13).

Dieulafoy lesions: Dieulafoy lesions are a rare but important cause of obscure gastrointestinal bleeding. While their pathogenesis is unclear, histopathological studies have demonstrated large 'calibre-persistent' submucosal arterioles that bleed through a pinhole erosion in the epithelium of the gastric fundus (14). Because the overlying mucosa is normal, Dieulafoy lesions are typically difficult to identify endoscopically in the absence of active hemorrhage. While these lesions are invariably found within $6 \mathrm{~cm}$ of the gastroesophageal junction on the lesser curve of the stomach, similar bleeding sources have been reported in the duodenal bulb and rarely in the jejunum, colon or rectum (15). Once identified, Dieulafoy lesions can be treated effectively by endoscopic injection, electrocautery, laser ablation or surgery (16).

Small bowel neoplasms: Tumours of the small intestine are considered to be relatively uncommon but are identified in up to $26 \%$ of patients with obscure gastrointestinal bleeding, particularly in those under 50 years of age $(17,18)$. Benign primary tumours of the small bowel that can present with hemorrhage include adenomas, leiomyomas and lipomas, while malignant small bowel neoplasms include adenocarcinomas, lymphomas, leimyosarcomas and lymphomas. Metastases to the gastrointestinal tract have been associated with primary tumours of the skin (particularly melanoma), ovary, bladder, breast, lung and pancreas (19).

Meckel's diverticulum: A Meckel's diverticulum is a congenital anomaly of the gut that is attributed to incomplete obliteration of the intestinal end of the embryonic duct. While most lesions are asymptomatic, up to $16 \%$ may contain ectopic gastric mucosa, which is prone to peptic ulceration and, hence, hemorrhage. Asymptomatic Meckel's diverticula are discovered incidentally at laparotomy for appendectomy in $1 \%$ to $2 \%$ of patients, and predominantly in males (20). If clinically suspected, diverticula that contain oxyntic mucosa can be localized noninvasively using ${ }^{99 \mathrm{~m}}$ technetium-pertechnetate scintigraphy (21). However, not all bleeding diverticula contain gastric mucosa, and a negative scan does not necessarily exclude them as the bleeding source (20). Meckel's diverticula account for a substantial number of cases of small bowel hemorrhage in young adult males (22).

Other diverticula: Although jejunal and duodenal diverticula are unusual sources of obscure bleeding, they can be found in $1 \%$ to $2 \%$ and $5 \%$ to $20 \%$ of asymptomatic individuals, respectively, in autopsy, radiology and endoscopy series (23-27). However, complications appear to be rare and develop in fewer than $20 \%$ of afflicted individuals (27). In one retrospective series, hemorrhage was the most common complication of duodenal diverticula but was relatively rare among jejunoileal lesions, which more often presented with perforation, abscess or malabsorption (27). Small bowel diverticula can account for intermittent overt bleeding at any age but are most commonly diagnosed in the sixth and seventh decades of life.
Vasculoenteric fistulae: An aortoenteric fistula is a rare lesion that may occur spontaneously or more commonly as a late complication of reconstructive aortic surgery. Such fistulas may form between the graft prosthesis and any portion of the gastrointestinal tract, but most commonly involve the third part of the duodenum. Their classic presentation is a brisk bleed that stops spontaneously, the herald hemorrhage, only to be followed by massive exsanguination 24 to $48 \mathrm{~h}$ later. Occasionally, however, aortoenteric fistulae may present with intermittent overt bleeding over a period of several months (28). In such patients, the diagnosis can be made only if the physician maintains a high index of suspicion and carries out appropriate diagnostic studies including full duodenoscopy, computed tomography and angiography.

Hemobilia: Acute hemobilia classically presents with the triad of jaundice, right upper quadrant abdominal pain and hematemesis. Hemobilia may complicate tumours of the hepatic parenchyma and biliary tree, cholelithiasis, ascariasis and invasive hepatobiliary procedures such as percutaneous liver biopsy, percutaneous transhepatic cholangiography, endoscopic retrograde cholangiopancreatography and surgical cholecystoenterostomy (29). While urgent duodenoscopy in a patient with acute hemobilia may reveal bleeding from the papilla, many patients bleed intermittently and the diagnosis can be overlooked unless considered. Treatment of refractory hemobilia usually requires resection of the responsible lesion, arterial ligature or angiographic embolization.

Hemosuccus pancreaticus: Recurrent gastrointestinal hemorrhage through the pancreatic duct has been reported in association with chronic pancreatitis (30). A peripancreatic artery typically is eroded by a pancreatic pseudocyst, or develops an aneurysm that erodes into the pancreatic duct or gastric lumen. Splenic artery aneurysms may calcify and become apparent on standard abdominal flat plates. Treatment is largely surgical, although selective arteriography and embolization of a peripancreatic aneurysm has been reported (31).

Vasculitis: The gastrointestinal tract is affected in a substantial proportion of patients with systemic vasculitis (32). Overt gastrointestinal hemorrhage has been reported in association with isolated leukocytoclastic vasculitis, systemic lupus erythematosus, Henoch-Schövlein purpura, cytomegalovirus (CMV)-associated vasculitis, Behçet's disease and Wegener's granulomatosis (33-38). Endoscopy may reveal local hyperemia, mucosal purpura or the typical features of idiopathic inflammatory bowel disease $(32,39-41)$. Abdominal radiographs may be normal or demonstrate thumb printing or pneumatosis intestinalis. Definitive diagnosis requires biopsy tissue for immunofluorescent staining and may only be achieved after laparotomy for an acute episode of refractory hemorrhage or perforation $(32,33,36)$.

Hiatal hernia: In patients with large hiatal hernias, linear erosions of gastric folds at the level of the diaphragm have been reported and may be associated with chronic, obscure blood loss (42). These so-called 'Cameron ulcers' can be overlooked at initial endoscopic evaluation but should be specifically sought in patients with obscure bleeding and a 


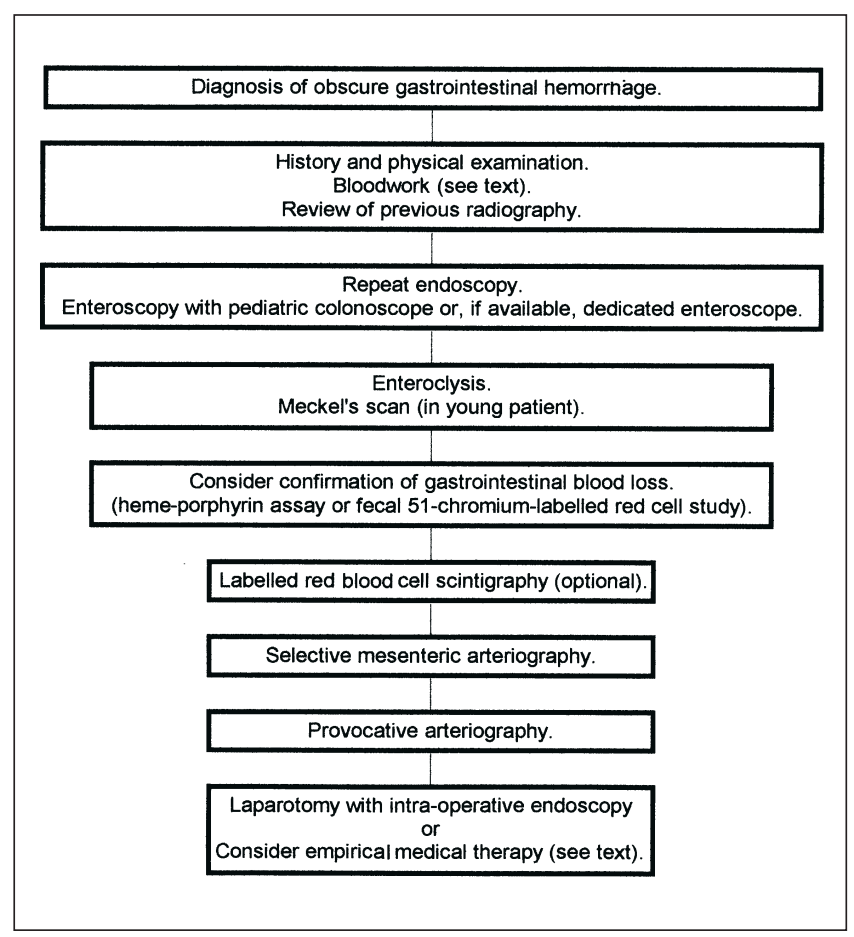

Figure 1) Proposed sequence of investigation in patients with obscure gastrointestinal hemorrhage. The algorithm should be terminated with the first positive result. The approach to individual cases may vary, and not all patients require full investigation

hiatal hernia. While most Cameron ulcers appear to respond acutely to aggressive acid-suppressive therapy, recurrence is common and may provide an indication for surgical reduction of the hernia (43).

\section{INVESTIGATION}

The diagnostic evaluation of patients with obscure gastrointestinal bleeding includes endoscopy of the upper and lower gastrointestinal tract, radionuclide scintigraphy, selective visceral arteriography and even exploratory surgery. Enteroscopy is increasingly available and fast becoming a standard diagnostic tool. As a general rule, the clinician should proceed from the simplest and least invasive tests to the more complex and invasive procedures (Figure 1).

Repeat endoscopy and colonoscopy: A repeat esophagogastroduodenoscopy and colonoscopy by an experienced endoscopist are mandatory in all patients with unidentified bleeding from the gastrointestinal tract. An upper endoscopy should also be performed using a colonoscope, whose tip can be advanced beyond the ligament of Treitz to examine the proximal jejunum. In this setting, the smaller diameter of a pediatric colonoscope may be better tolerated by patients. The colonoscopy should follow meticulous cleansing of the colon to allow detailed inspection of the mucosa for angioectasias. Excessive insufflation of the cecum and ascending colon can blanche angioectasias and should be carefully avoided because they are slow to refill. Angioectasia can also be difficult to detect in the presence of severe anemia, and tranfusion before endoscopy may augment the diagnostic yield. When thorough repeat esophagogastroduodenoscopy and colonoscopy are confidently reported as normal, the site of hemorrhage is usually localized to the small bowel.

Enteroscopy: Endoscopic imaging of the small intestine is most commonly attempted by oral passage of an adult or pediatric colonoscope to the proximal jejunum. However, specialized centres may also have access to sonde or dedicated push enteroscopes. The sonde enteroscope is passed orally or transnasally, advanced to the ligament of Treitz piggybacked to a regular endoscope and then released. Guidewire approaches to initial placement of the instrument are also available. Once in the distal duodenum, a balloon on the instrument's tip is inflated and a prokinetic agent is administered parenterally to facilitate passive advance by peristalsis. The endoscopic assessment is then performed during withdrawal of the instrument. In experienced hands, sonde enteroscopes, which measure up to $400 \mathrm{~cm}$ in length, allow visualization of the distal jejunum in up to $90 \%$ and the terminal ileum in $60 \%$ of cases $(44,45)$. However, most of these devices do not permit tip deflection, have no biopsy channel, cannot accurately localize lesions for subsequent intervention, and require 4 to $8 \mathrm{~h}$ to complete examination of the small intestine.

In contrast, the push enteroscope is inserted orally and advanced by the endoscopist much like a regular endoscope, although it often requires the assistance of fluoroscopy and/or external abdominal compression. While push enteroscopes generally cannot be advanced as far as sonde enteroscopes into the distal small bowel, they usually are equipped with a deflectable tip for better mucosal inspection, and a biopsy channel for endoscopic intervention. An overtube can be used to prevent looping of the endoscope shaft in the stomach and duodenum. Most authors report routine placement of push enteroscopes, which measure $2 \mathrm{~m}$ to $3 \mathrm{~m}$ in length, $30 \mathrm{~cm}$ to $150 \mathrm{~cm}$ beyond the ligament of Treitz (4648).

In patients investigated for obscure gastrointestinal blood loss, enteroscopy has revealed a bleeding source in $20 \%$ to $75 \%$ of patients undergoing examination at experienced centres $(44,46,47,49-51)$. In most of these series, approximately half of the lesions were identified proximal to the ligament of Treitz and within reach of a conventional endoscope but had been overlooked. Thus, the true incremental diagnostic yield of enteroscopy after careful repeat examination by an expert endoscopist using a conventional endoscope or pediatric colonoscope remains unclear. Angioectasias and small bowel tumours appear to be the two most common lesions identified in the small bowel at enteroscopy, although the former can be confused with traumatic submucosal hemorrhage. Angioectasias may be amenable to definitive endoscopic therapy through injection or electrocautery, while tumours can be removed by snare (if small) or biopsied to direct further management.

Small bowel radiography: Single contrast barium radiography of the small bowel has a low diagnostic yield in patients investigated for obscure bleeding (52). In contrast, small bowel enteroclysis may detect a potential source in $10 \%$ to 
$20 \%$ of these patients $(17,53)$ and is considered the gold standard for detection of small bowel tumours and diverticula (54). However, even double-contrast barium radiography may fail to detect superficial lesions such as mucosal angioectasias, and hence a negative study cannot exclude the small bowel as a bleeding source. Barium imaging has no role in the evaluation of patients with active bleeding because residual contrast can interfere with subsequent endoscopic or mesenteric arteriographic procedures.

Nuclear-labelled red cell scans: Scintigraphy following intravenous injection of red blood cells labelled with ${ }^{99 m}$ technetium is a technique commonly used to localize low grade but clinically overt gastrointestinal bleeding. The long intravascular half-life of the labelled cells allows sequential imaging for up to $24 \mathrm{~h}$ after injection, and extravasation may be detected with a bleeding rate as low as 0.1 to $0.2 \mathrm{~mL} / \mathrm{min}$ (55). In positive studies, the localization of colonic bleeding often can be straightforward because the large bowel is relatively fixed anatomically and because extravasated blood shows little transit. However, bleeding at the splenic and hepatic flexures may be obscured by pooling of technetium in the liver and spleen and give a false negative result.

The use of scintigraphy in the diagnosis of obscure bleeding is limited by its relative inability to localize bleeding in the small intestine, where most bleeding sources are often identified. Thus, red blood cell scanning in this population may do little to direct further therapy or surgical resection. Nevertheless, scintigraphy is relatively safe, and detects low grade or intermittent bleeding, with a sensitivity of approximately $75 \%$ (56). A negative scan implies a good prognosis and may indicate that arteriography will not reveal a bleeding site (57-58).

Meckel's scan: Radionuclide scintigraphy may allow detection of a Meckel's diverticulum by intravenous injection of $99 \mathrm{~m}$ technetium-pertechnetate, which is taken up preferentially by ectopic gastric mucosa. Using this technique, Sfakianakis and Conway (21) reported a sensitivity of $85 \%$ and a specificity of $95 \%$ in a referral population. The sensitivity of the standard Meckel's scan may be increased by priming the patient with pentagastrin to stimulate mucosal uptake, or with an $\mathrm{H}_{2}$ receptor antagonist to prolong the residence time of the isotope (59-60). False positive results have been reported in inflammatory bowel disease and enteric duplication or gastrogenic cysts $(21,61)$, while false negative results have been reported in adult patients (62).

Arteriography: The role of selective visceral arteriography as a diagnostic and therapeutic intervention in active gastrointestinal hemorrhage is clearly established in the literature. Although active bleeding in excess of $0.5 \mathrm{~mL} / \mathrm{min}$ is necessary to detect frank extravasation, arteriography may be useful in patients with obscure hemorrhage who are not actively bleeding. For example, a vascular tuft or early filling vein may suggest an angioectasia, or a tumour blush may localize a small bowel neoplasm. Despite the intermittent nature of many obscure gastrointestinal bleeds, a diagnostic yield of $44 \%$ has been reported using angiography after an extensive noninvasive workup (63). However, selective mesenteric ar- teriography is a sophisticated technique that requires expensive digital equipment, and highly specialized radiographic and radiological training.

Repeat arteriography in 'obscure bleeders' with an initial negative study is a controversial but occasionally rewarding procedure. The 'second look' may coincide fortuitously with an episode of bleeding or, more commonly, may fill different branch vessels to increase the diagnostic yield (64).

In selected patients, 'pharmacoangiography' may enhance the yield of 'second look' arteriography. In these techniques, a vasodilator (eg, tolazoline), anticoagulant (eg, heparin) or thrombolytic agent (eg, urokinase) is administered before arteriography to prolong, augment or reactivate hemorrhage. Various reports have described positive provocative angiograms in challenging patients with extensive prior negative workup (65-68). However, because lifethreatening hemorrhage is an obvious potential complication of pharmacoangiography, patients must provide informed consent and full resuscitation facilities must be available.

Laparotomy: When all prior diagnostic modalities have failed to disclose a source of clinically significant bleeding, exploratory laparotomy should be considered. This may be particularly rewarding in patients under the age of 50 years, in whom small bowel tumours and Meckel's diverticula are more commonly found (2). In patients who are actively bleeding, intraoperative red blood cell scintigraphy or mesenteric arteriography has been suggested (69). When a source is identified at angiography, direct injection of methylene blue dye into the culprit vessel may assist surgical resection (70).

Intraoperative endoscopy is perhaps the most useful adjunct to diagnostic laparotomy. In most cases, once the abdominal cavity is opened, a colonoscope is passed orally and advanced by the endoscopist to the proximal jejunum. The surgeon then pleats the bowel over the endoscope until the cecum is intubated. Alternatively, a surgical enterotomy can be created to allow caudad and cephalad passage of a sterilized gastroscope. Novel techniques for the laparoscopic assistance of enteroscopy have also been described (71).

Careful inspection of the mucosa while the endoscope is advanced is advocated to avoid false positive findings due to endoscopic trauma when the bowel is revisualized during withdrawal of the instrument (72). With the lights of the operating room dimmed and the bowel transilluminated by the endoscope, the vascular pattern of the gut can be carefully examined both externally by the surgeon and intraluminally by the endoscopist. Cross-clamping the terminal ileum is reported to help maintain small bowel insufflation and improve visualization (73). However, the endoscopist must remember to deflate the bowel carefully as the endoscope is withdrawn to facilitate surgical closure of the abdomen. When a bleeding source is identified, treatment can be performed endoscopically (eg, electrocautery, injection) or by surgical resection, depending on the nature of the lesion. Because of the extensive manipulation of the small bowel, a prolonged postoperative ileus can be anticipated. 
Intraoperative endoscopy provides a diagnosis in the majority of patients investigated for obscure bleeding $(18,74)$. Lewis et al (18) investigated 137 such patients and performed intraoperative endoscopy in 53 cases. The source of bleeding was identified in $83 \%$ of patients, but the postoperative mortality rate was still substantial (7.5\%) and largely attributed to uncontrolled hemorrhage. Furthermore, bleeding recurred in $26 \%$ of these challenging patients despite ostensibly appropriate surgery. Thus, while laparotomy is a useful tool, it should be considered an intervention of last resort in patients with obscure gastrointestinal hemorrhage.

\section{MANAGEMENT APPROACH}

The approach to any patient with gastrointestinal hemorrhage is determined by the considered site, extent and rate of bleeding and, importantly, the age of the patient. As with any form of bleeding, the primary consideration should be to provide supportive care, including hemodynamic stabilization, reversal of coagulopathy and blood product transfusion. The strategy proposed below is for patients who are hemodynamically stable with recurrent or persistent hemorrhage requiring transfusion.

In such patients, the history and physical examination should be repeated carefully because important elements may have been overlooked or not volunteered initially. Any overt gastrointestinal blood loss in the form of hematemesis, melena or hematochezia should be carefully confirmed and may help to localize bleeding to the upper or lower digestive tract. Variation in the rate of blood loss with menstruation, menopause or pregnancy, or a family history of recurrent epistaxis may suggest the diagnosis of hereditary hemorrhagic telangiectasia. Any patient with a past history of aortic surgery must be assumed to have an aortoenteric fistula until proven otherwise. Other comorbid illnesses such as chronic renal failure or aortic stenosis are associated with degenerative angioectasias, although this relationship is confounded by age.

On physical examination, the clinician should assess the abdomen for surgical scars and carefully inspect the skin for the cutaneous manifestations of the blue rubber-bleb nevus syndrome, Peutz-Jeghers syndrome or hereditary hemorrhagic telangiectasia. The presence of peripheral adenopathy or hepatosplenomegaly may raise suspicion of a lymphoproliferative disorder. Stigmata of chronic liver disease including splenomegaly may suggest underlying portal hypertension with varices or portal hypertensive gastropathy.

Routine laboratory testing including complete blood count, prothrombin time and active partial thromboplastin time should be performed in all such patients to exclude coagulation defects, functional platelet disorders and blood dyscrasias. It is vital that films from any previous radiological investigation be reviewed by an experienced gastrointestinal radiologist to ensure their adequacy and to confirm that no possible lesions were overlooked.

The urgency and extent of further diagnostic workup are determined by the patient's overall clinical picture. In all patients, a repeat upper and lower endoscopic examination by the most experienced endoscopist is mandatory because previously undetected lesions may become apparent. Where possible, a push or Sonde enteroscope should be used to visualize the proximal small bowel. However, because such instruments are unfamiliar or unavailable to most endoscopists, upper endoscopy using a pediatric colonoscope is a reasonable and useful alternative. If these examinations fail to provide a diagnosis, more invasive investigation is needed only if bleeding is significant enough to require hospitalization and/or repeated blood transfusion, or if the clinical scenario mandates that an underlying malignancy should be excluded.

At the next level of investigation, small bowel enteroclysis should be performed by an experienced gastrointestinal radiologist to exclude reliably a small bowel tumour not seen at enteroscopy. Young adults should also undergo a ${ }^{99 \mathrm{~m}}$ technetium-pertechnetate scan to rule out a rare but easily treated Meckel's diverticulum. If these tests are performed adequately and are negative, and if there is no further clinically significant bleeding, most patients can be managed conservatively.

More often, however, patients with a history of obscure gastrointestinal hemorrhage continue to provide signs of intermittent low grade bleeding. For patients who present with recurrent transfusion-dependent anemia, it may be prudent at this point to confirm that blood loss is occurring from the gastrointestinal tract. This can be accomplished by using either a quantitative heme-porphyrin assay (HemoQuant Mayo Medical Laboratories, Rochester, Minnesota) or a ${ }^{51}$ chromium-tagged red blood cell scan, although the latter appears to be more accurate (75).

If documented bleeding persists and is considered clinically significant, a ${ }^{99 \mathrm{~m}}$ technetium-labelled red blood cell scan can be performed, with serial imaging over 24 to $48 \mathrm{~h}$. If the scan is positive, repeat endoscopy, colonoscopy or enteroscopy should be undertaken by an experienced endoscopist with close attention to the area of apparent extravasation. Although controversial, medically fit patients with recurrent bleeding localized to the right colon despite negative colonoscopy may be considered for an empirical right hemi- or subtotal colectomy for presumed angioectasia (76).

If radionuclide scintigraphy is uninformative, or not indicated because the bleeding is too intermittent or slow, elective visceral arteriography should be performed to look for features of angioectasia (vascular tufts or early filling veins) or tumour (vascular blush). Positive findings can be managed endoscopically or surgically, depending on the location and number of lesions. If arteriography is negative, but intermittent bleeding persists, selected patients should be admitted for provocative arteriography following infusion of heparin or a thrombolytic agent to induce or augment hemorrhage.

For patients in whom the above investigations fail to yield a diagnosis but who continue to bleed, elective exploratory laparotomy may be considered, especially if the patient is young. Intraoperative endoscopy should be performed as 
an adjunct, although the specific technique applied depends on local expertise and familiarity.

If a suitable patient refuses surgery, or poses a significant operative risk, empirical medical intervention is an alternative that can be both diagnostic and therapeutic. The majority of patients with obscure gastrointestinal hemorrhage ultimately can be proven, by exhaustive investigation, to have angioectasias of the small bowel. Combination hormone therapy with estrogen and progesterone may reduce blood loss from these lesions, with a favourable adverse effect profile in selected patients (3). Subcutaneous octreotide may offer a similar benefit but at substantially higher cost (62).

\section{SUMMARY}

The diagnosis and management of patients with obscure gastrointestinal bleeding pose a significant challenge to the clinician and may consume a disproportionate amount of medical attention and health care resources. Such patients often require multiple hospitalizations and blood transfusions, and an extensive diagnostic evaluation including repeated endoscopy, barium contrast radiography, radionuclide scans, arteriography and even laparotomy. However, a logical stepwise approach should allow a diagnosis to be achieved in the majority. Common sources of obscure hemorrhage in patients who undergo definitive investigation include angioectasias and small bowel tumours. Discrete lesions may be amenable to endoscopic ablation or surgical resection. When no cause is found despite extensive investigation, a trial of empirical hormonal therapy for presumptive angioectasias may be warranted.

\section{REFERENCES}

1. Spiller RC, Parkins RA. Recurrent gastrointestinal bleeding of obscure origin: report of 17 cases and a guide to logical management. Br J Surg 1983;70:489-93.

2. Lewis BS. Small intestinal bleeding. Gastroenterol Clin North Am 1994;23:67-91.

3. Marshall JK, Hunt RH. Hormonal therapy for bleeding gastrointestinal mucosal vascular abnormalities: a promising alternative. Eur J Gastroenterol Hepatol 1997;9:521-5.

4. Camilleri M, Chadwick VS, Hodgson HJ. Vascular anomalies of the gastrointestinal tract. Hepatogastroenterology 1984;31:149-53.

5. Crespi M, Delvaux M, Schaprio M, Venables C, Zwiebel F. Working Party Report by the Committee for Minimal Standards of Terminology and Documentation in Digestive Endoscopy of the European Society of Gastrointestinal Endoscopy. Minimal Standard of terminology for a computerized endoscopic database. Ad hoc Task Force of the Committee. Am J Gastroenterol 1996;91:191-216.

6. Thompson JN, Hemingway AP, McPherson GA, Rees HC, Allison OJ, Spencer J. Obscure gastrointestinal hemorrhage of small-bowel origin. Br Med J (Clin Res Ed) 1984;288:1663-5.

7. Chey WD, Hasler WL, Bochenstedt PL. Angiodysplasia and von Willebrand's disease type IIB treated with estrogen/progesterone therapy. Am J Hematol 1992;41:276-9.

8. Koch HJ, Escher GC, Lewis JS. Hormonal management of hereditary hemorrhagic telangiectasia. JAMA 1952;149:1376-80.

9. McGee RR. Estrogen-progesterone treatment for gastrointestinal bleeding in hereditary hemorrhage telangiectasia. South Med J 1979;72:1503.

10. Hunt RH. Angiodysplasia of the gut. In: Bennett JR, Hunt RH, eds. Therapeutic Endoscopy and Radiology of the Gut, 2nd edn. London: Chapman and Hall Medical, 1990:175-89.

11. Boley SJ, Brandt LJ, Mitsudo SM. Vascular lesions of the colon. Adv Intern Med 1984;29:301-26.

12. Jabbari M, Cherry R, Lough JO, Daly DS, Kinnear OG, Goresky CA.
Gastric antral vascular ectasia: the watermelon stomach. Gastroenterology 1984;87:1165-70.

13. Lingenfelser T, Krige JE. The stomach in cirrhosis. The legend of Proteus retold. J Clin Gastroenterol 1993;17:92-6.

14. Veldhuyzen van Zanten SJO, Bartelsman JFWM, Schipper MEI, Tytgat GNJ. Recurrent massive hematemesis from Dieulafoy vascular malformations - review of 101 cases. Gut 1986;27:213-22.

15. Dy NM, Gostout CJ, Balm RK. Bleeding from the endoscopically-identified Dieulafoy lesion of the proximal small intestine and colon. Am J Gastroenterol 1995;90:108-11.

16. Reilly HF III, Kawas FH. Dieulafoy's lesion: diagnosis and management. Dig Dis Sci 1991;36:1702-7.

17. Moch A, Herlinger H, Kochman ML, Levine MS, Rubesin SE, Laufer I. Enteroclysis in the evaluation of obscure gastrointestinal bleeding. Am J Roentgenol 1994;163:1381-4.

18. Lewis MPN, Khoo DE, Spencer J. Value of laparotomy in the diagnosis of obscure gastrointestinal bleeding. Gut 1995;37:187-90.

19. Washington K, McDonagh D. Secondary tumours of the gastrointestinal tract: surgical pathologic findings and comparison with autopsy survey. Mod Pathol 1995;8:427-33.

20. Matsagas MI, Fatouros M, Koulouras B, Giannoukas AD. Incidence, complications, and management of Meckel's diverticulum. Arch Surg 1995; 130:143-6.

21. Sfakianakis GN, Conway JJ. Detection of ectopic gastric mucosa in Meckel's diverticulum and in other aberrations: pathophysiology and 10-year clinical experience. J Nucl Med 1981;22:732-8.

22. Brown CK, Olshaker JS. Meckel's diverticulum. Am J Emerg Med 1988;6:157-64.

23. Ackermann W. Diverticular and variation of the duodenum. Ann Surg 1943;117:403-13.

24. Chitambar IA. Duodenal diverticula. Surgery 1953;33:768-91.

25. Osnes M, Lootveit T, Larsen S, Aune S. Duodenal diverticula and their relationship to age, sex, and biliary calculi. Scand J Gastroenterol 1981;16:103-7.

26. Duarte B, Nagy KK, Cintron J. Perforated duodenal diverticulum. Br J Surg 1992;79:877-81.

27. Akhrass R, Yaffe MB, Fischer C, Ponsky J, Shuck JM. Small bowel diverticulosis: perceptions and reality. J Am Coll Surg 1997;184:383-8.

28. Antinori CH, Andrew CT, Santaspirt JS, et al. The many faces of aortoenteric fistulas. Am Surg 1996;62:344-9.

29. Bloechle C, Izbicki R, Rashed MYT, et al. Hemobilia: presentation, diagnosis, and management. Am J Gastroenterol 1994;89:1537-40.

30. Risti B, Marincek B, Jost R, Decurtins M, Ammann R. Hemosuccus pancreaticus as a course of obscure upper gastrointestinal bleeding: three cases and literature review. Am J Gastroenterol 1995;90:1878-80.

31. Steckman ML, Dooley MC, Jaques PF, Powell DW. Major gastrointestinal hemorrhage from peripancreatic blood vessels in pancreatitis. Treatment by embolotherapy. Dig Dis Sci 1984;29:486-97.

32. Camilleri M, Pusey CD, Chadwick VS, Rees AJ. Gastrointestinal manifestations of systemic vasculitis. Q J Med 1982;52:141-9.

33. Agha FP, Hostrant TT, Keren DF. Leucocytoclastic vasculitis (hypersensitivity angiitis) of the small bowel presenting with severe gastrointestinal hemorrhage. Am J Gastroenterol 1986;81:195-8.

34. Zizic TM, Shulman LE, Stevens MB. Colonic perforations in systemic lupus erythematosus. JAMA 1975;206:1569.

35. Sackier JM, Kelly SB, Clarke D, Wood CB. Small bowel hemorrhage due to cytomegalovirus vasculitis. Gut 1991;32:1419-20.

36. Powers BJ, Brown G, Williams RW, Speers W. Leukocytoclastic vasculitis not associated with Henoch-Schonlein purpura causing recurrent massive painless gastrointestinal hemorrhage. Am J Gastroenterol 1992;87:1191-3.

37. Solans R, San Jose A, Bosch JA. [Massive intestinal hemorrhage as presentation of Behcet's disease]. Med Clin (Barc) 1996;106:239.

38. Gastrointestinal hemorrhage complicating Wegener's granulomatosis. Br Med J (Clin Res Ed) 1985;291:1275-6.

39. Tsuchiya M, Okazaki I, Asakura H, Okubo T. Radiographic and endoscopic features of colonic ulcers in systemic lupus erythematosus. Am J Gastroenterol 1975;664:277.

40. Kurlander DJ, Kirsner JB. The association of chronic nonspecific inflammatory bowel disease with lupus erythematosus. Ann Intern Med 1964;60:799.

41. Tung SY, Wu CS, Chen PC, Kuo YC. [Clinical observation of 
Henoch-Schonlein purpura: focus on gastrointestinal manifestations and endoscopic findings]. Chang Keng I Hsueh 1994;17:347-51.

42. Cameron AJ, Higgins JA. Linear gastric erosion: a lesion associated with large diaphragmatic hernia and chronic blood loss in anemia. Gastroenterology 1986;91:338-42.

43. Weston AP. Hiatal herna with Cameron ulcers and erosions. Gastrointest Endosc Clin N Am 1996;6:671-9.

44. Berner JS, Mauer K, Lewis BS. Push and sonde enteroscopy for the diagnosis of obscure gastrointestinal bleeding. Am J Gastroenterol 1994;89:2139-42.

45. Lewis BS, Kornbluth A, Waye JD. Small bowel tumours: yield of enteroscopy. Gut 1991;37:673-7.

46. Chong J, Tagle M, Barkin JS, Reiner DK. Small bowel push-type fiberoptic enteroscopy for patients with occult gastrointestinal bleeding or suspected small bowel pathology. Am J Gastroenterol 1994;89:2143-6.

47. Davies GR, Benson MJ, Gertner DJ, Van Someren RM, Rampton DS, Swain CP. Diagnostic and therapeutic push type enteroscopy in clinical use. Gut 1995;37:346-52.

48. Rossini FP, Arrigoni A, Pennazio M. Clinical enteroscopy. J Clin Gastroenterol 1996;22:231-6.

49. Lewis BS, Waye JD. Chronic gastrointestinal bleeding of obscure origin: role of small bowel enteroscopy. Gastroenterology 1988;94:117-20.

50. Landi B, Tkoub M, Gaudric M, et al. Diagnostic yield of push-type enteroscopy in relation to indication. Gut 1998;42:421-5.

51. Pennazio M, Rossini FP. Diagnostic efficacy and impact on therapeutic decisions of push enteroscopy in the investigation of obscure gastrointestinal bleeding. Endoscopy 1997;29:E32 (Abst).

52. Rabe F, Becker G, Begozzi MJ, Miller RE. Efficacy study of the small-bowel examination. Radiology 1981;140:47-50.

53. Rex DK, Lappas JC, Maglinte DD, Mackewski MC, Kopecky KA, Cockerill EM. Enteroclysis in the evaluation of suspected gastrointestinal bleeding. Gastroenterology 1989;97:58-60.

54. Maglinte DD, Elmore MF, Chernish SM, et al. Enteroclysis in the diagnosis of chronic, unexplained gastrointestinal bleeding. Dis Colon Rectum 1985;28:403-5.

55. Smith R, Copely DJ, Bolen FH. 99mTc RBC scintigraphy: correlation of gastrointestinal bleeding rates with scintigraphic findings. AJR Am J Roentgenol 1987;148:869-74.

56. Ohri SK, Desa LA, Lee H, et al. Value of scintigraphic localization of obscure gastrointestinal bleeding. J R Coll Surg Edinb 1992;37:328-32.

57. Jacobson AF, Cerqueira MD. Prognostic significance of late imaging results in technetium-99m-labelled red blood cell gastrointestinal bleeding studies with early negative images. J Nucl Med 1992:33:202-7.

58. Ng DA, Opelka FG, Beck DE, et al. Predictive value of technetium Tc 99m-labelled red cell scintigraphy for positive angiogram in massive lower gastrointestinal hemorrhage. Dis Colon Rectum 1997;40:471-7.

59. Sfakianakis GN, Anderson GF, King DR, et al. The effect of gastrointestinal hormones on the pertechnetate imaging of ectopic gastric mucosa in experimental Meckel's diverticulum. J Nucl Med 1981;22:678-83.

60. Yeker D, Buyukunal C, Benli M, et al. Radionuclide imaging of Meckel's diverticulum: cimetidine versus pentagastrin plus glucagon. Eur J Nucl Med 1984;9:316-9.

61. Berquist TH, Nolan NG, Stephens DH, Carlson HC. Specificity of Tc-99 pertechnetate in scintigraphic diagnosis of Meckel's diverticulum: a review of 100 cases. J Nucl Med 1976;17:465-9.

62. Schwartz MJ, Lewis JH. Meckel's diverticulum: pitfalls in scintigraphic detection in the adult. Am J Gastroenterol 1984;79:611-8.

63. Rollins ES, Picus D, Hicks ME, Darcy MD, Bower BL, Kleinhoffer MA. Angiography is useful in detecting the source of chronic gastrointestinal bleeding of obscure origin. AJR Am J Roentgenol 1991;156:385-8.

64. Lau WY, Ngan H, Chu KW, Yeun WK. Repeat selective visceral angiography in patients with gastrointestinal bleeding of obscure origin. Br J Surg 1989;76:226-9.

65. Koval G, Benner KG, Rosch J, Kozak BE. Aggressive angiographic diagnosis in acute lower GI hemorrhage. Dig Dis Sci 1987;32:248-53.

66. Glickerman J, Kowdley KV, Rosch J. Urokinase in gastrointestinal bleeding. Radiology 1988;168:375-6.

67. Rosch J, Keller FS, Wawrukiewicz AS. Pharmacoangiography in the diagnosis of recurrent massive lower GI bleeding. Radiology 1992;145:615-9.

68. Mernagh JR, Odonovan AN, Somers S, et al. Use of heparin in the investigation of obscure gastrointestinal bleeding. Radiology 1996;201(Suppl):384 .

69. Biener AB, Palestro C, Lewis BS, Katz LB. Intraoperative scintigraphy for active small bowel bleeding. Surg Gynecol Obstet 1990;171:388-92.

70. McDonald ML, Farnell MB, Stanson AW, Ress AM. Preoperative highly selective catheter localization of occult small intestinal hemorrhage with methylene blue. Arch Surg 1995;130:106-8.

71. Hakim PE, Saxe A. Laparoendoscopy (laparoscopy assisted enteroscopy) and partial resection of small bowel. Surg Endosc 1994;8:686-8.

72. Frank MS, Brandt LJ, Boley SJ. Iatrogenic submucosal hemorrhage: a pitfall of intraoperative endoscopy. Am J Gastroenterol 1987;75:209-10.

73. Szold A, Katz LB, Lewis BS. Surgical approach to occult gastrointestinal bleeding. Am J Surg 1992;163:90-3.

74. Rossini FP, Arrigoni A, Pennazio M. Octreotide in the treatment of bleeding due to angiodysplasia of the small intestine. Am J Gastroenterol 1993;88:1424-7.

75. Young GP, St John DJ, Lynch NM, McHutchinson JG, Barraclough D. Measurement of occult upper gastrointestinal tract blood loss: a direct comparison of radiochromium and haem-porphyrin assay techniques. J Gastroenterol Hepatol 1993;8:328-33.

76. Milewski PJ, Schofield PF. Massive colonic hemorrhage: the case for right hemicolectomy. Ann R Coll Surg Engl 1989;71:253-9. 


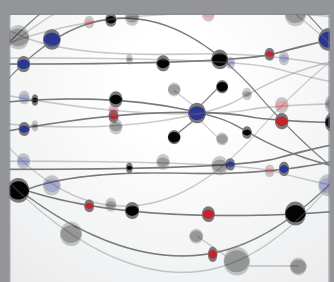

The Scientific World Journal
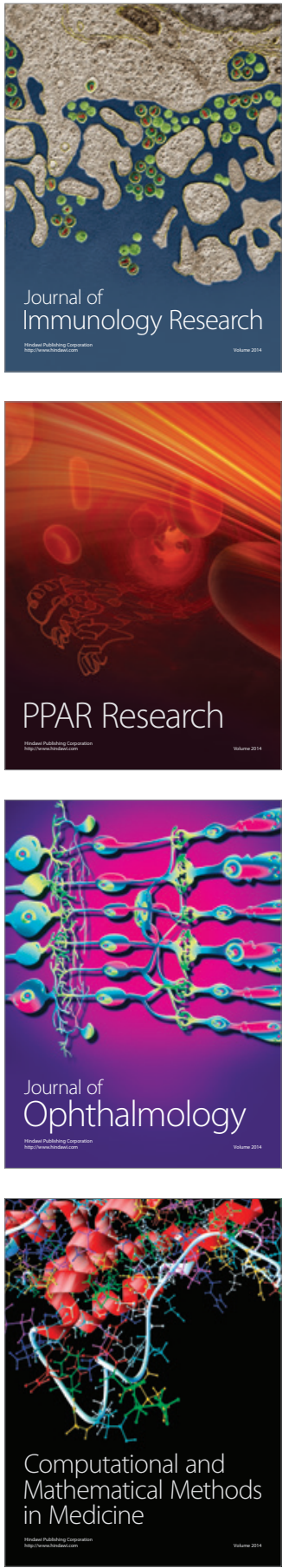

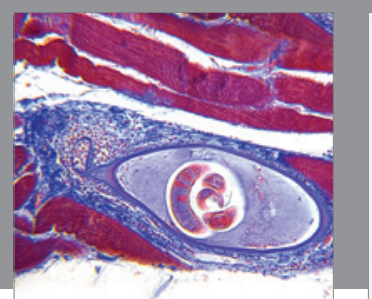

Gastroenterology Research and Practice

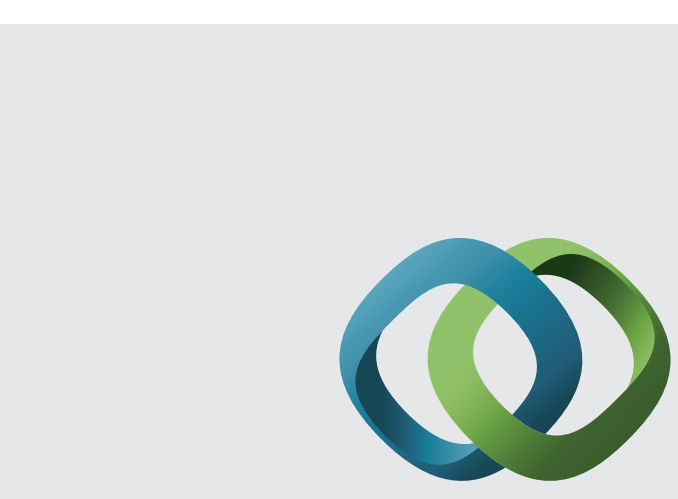

\section{Hindawi}

Submit your manuscripts at

http://www.hindawi.com
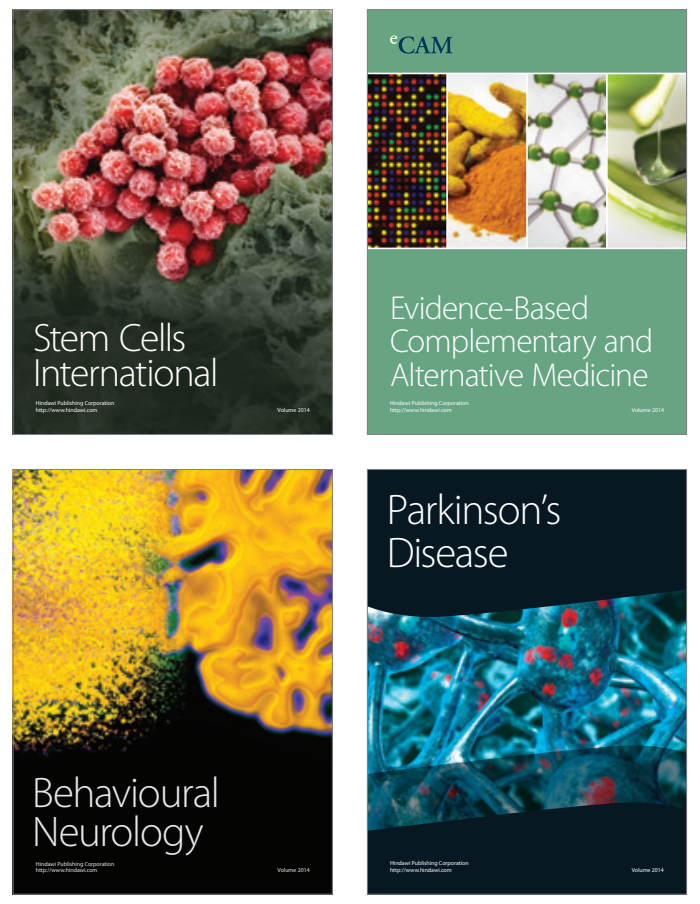
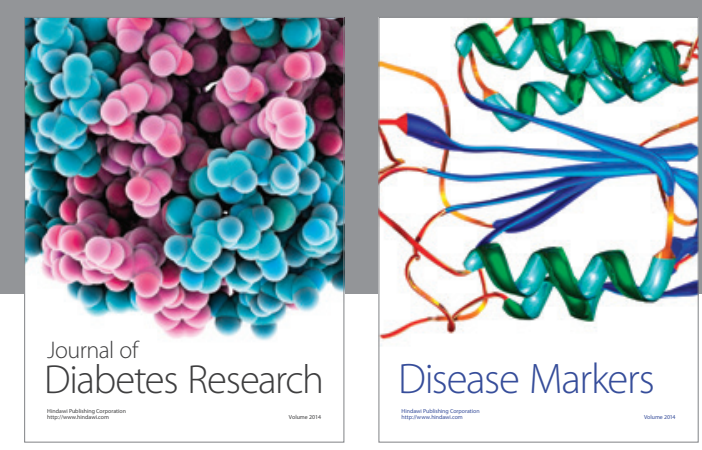

Disease Markers
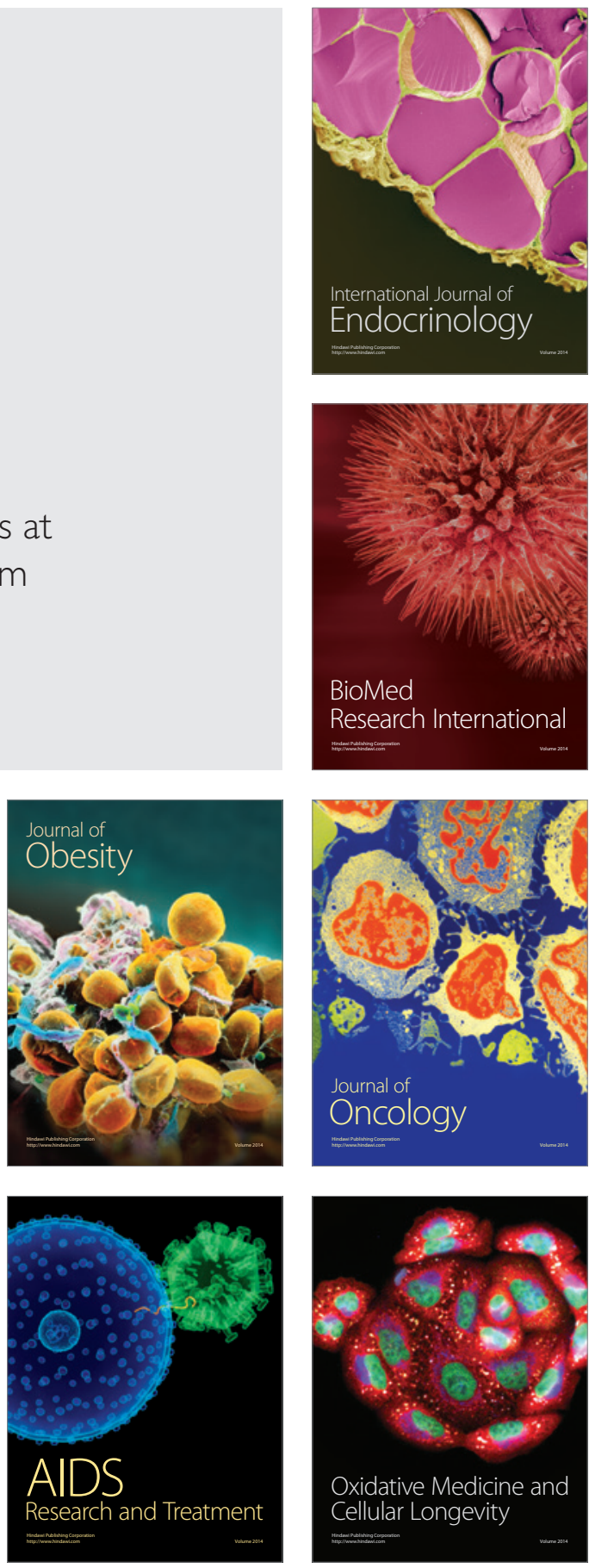